\title{
Non-ulcer dyspepsia: does Helicobacter pylori matter?
}

\author{
P Sahay, ATR Axon
}

\begin{abstract}
Summary
Non-ulcer dyspepsia is a heterogenous disorder characterised by chronic or recurrent abdominal or retrosternal discomfort lasting for more than four weeks for which no cause can be determined. Helicobacter pylori has been implicated as a potential cause in a subset of patients but the association has not been proven and $H$ pylori eradication in patients with non-ulcer dyspepsia has had variable results. Large well-controlled studies are needed to clarify the relationship.
\end{abstract}

Keywords: non-ulcer dyspepsia, Helicobacter pylori

\begin{tabular}{|l|}
\hline Helicobacter pylori \\
\hline Features: \\
- a spiral, Gram-negative rod with \\
4-6 unipolar flagellae. \\
- easy to culture under microaerobic \\
conditions on special media \\
- has an extremely high urease \\
activity \\
- colonises the sub-mucus layer of \\
the human gastric epithelium \\
predominantly in the antrum being \\
always related to cells derived from \\
gastric type mucosa \\
- diagnosis can be made by histology, \\
culture, CLO test, serology and \\
urea breath test \\
- modes of transmission could be \\
faecal-oral or oral-oral; this \\
explains the higher prevalence in \\
closed communities, disadvantaged \\
socio-economic groups and \\
developing countries
\end{tabular}

Box 1

Department of Gastroenterology, Scunthorpe General Hospital, Cliff Gardens, Scunthorpe, South Humberside, DN15 7BH, UK P Sahay

Department of Gastroenterology, Leeds General Infirmary, Leeds LS1 3EX, UK ATR Axon

Accepted 19 January 1995

\section{Introduction}

Dyspepsia is an extremely common gastroenterologic complaint consuming large amounts of medical and economic resources. It encompasses a spectrum of diseases from non-ulcer dyspepsia at one end of the scale to carcinoma of the stomach at the other. The label of non-ulcer dyspepsia is currently given to patients who present with dyspepsia but have either no demonstrable lesion in the upper gastrointestinal tract or have abnormalities of uncertain significance. It is important, therefore, that a positive approach to non-ulcer dyspepsia is pursued, though therapy at present remains largely empirical.

Non-ulcer dyspepsia is defined as chronic or recurrent upper abdominal or retrosternal discomfort lasting for more than four weeks with symptoms unrelated to exertion and for which no cause can be found on investigation. ${ }^{1}$ It is a heterogenous disorder which has been classified into various subgroups according to symptom clusters. These categories include 'ulcer-like', 'reflux-like', 'dysmotility-like', and 'non-specific' dyspepsia. ${ }^{2}$ Unfortunately, many patients fall into two or more groups and a sizeable proportion do not fit into any category. ${ }^{3}$

\section{Causes}

Non-ulcer dyspepsia was previously considered to be purely psychosomatic in origin but this is probably untrue in many cases. ${ }^{4}$ Abnormal upper gastrointestinal motility ${ }^{5}$ including delayed gastric emptying and post-prandial antral hypomotility together with visceral perception of bloating, earlier satiety, nausea and post-prandial distress are disturbances noted to be associated with increased sensitivity to gastric acid. ${ }^{6}$ These abnormalities have not, however, been identified in all patients.

Since its discovery, Helicobacter pylori has been implicated as a potential cause of non-ulcer dyspepsia in a subset of patients. ${ }^{7}$ Tytgat et al found $H$ pylori positivity in $50 \%$ of patients with functional dyspepsia. ${ }^{8}$ However, as $\mathrm{H}$ pylori also occurs in asymptomatic persons it is unclear whether or not it plays a pathogenic role in non-ulcer dyspepsia. Those who invoke $H$ pylori as a cause of non-ulcer dyspepsia stress that the gastrin release from antral $\mathrm{G}$ cells initiated by a meal or bombesin is elevated in infected subjects and returns to normal after $H$ pylori eradication. ${ }^{9,10}$ Toukan $e t$ al $^{11}$ found significantly increased number of neutrophils in the gastric mucosa of patients with non-ulcer dyspepsia.

Czinn $e t ~ a l^{12}$ noted a positive correlation between the severity of histologic gastritis and the severity of epigastric pain, nausea and flatulence. Moore and co-workers ${ }^{13}$ showed an inverse correlation between the degree of gastritis and post-prandial antral motor activity, suggesting that gastric mucosal inflammation may be associated with an alteration in gastric motility. Symptoms in $H$ pylori positive subjects are also more severe than in the uninfected non-ulcer dyspepsia ${ }^{14}$ and in population studies an increase in dyspeptic symptoms was observed in $H$ pylori infected subjects. ${ }^{15,16}$ Following eradication there was a significant and marked reduction noted in the symptoms over a period of one year when compared with the $H$ pylori positive patients. ${ }^{17}$

The temptation to attribute non-ulcer dyspepsia to $H$ pylori gastritis if no other cause is found on investigation has to be resisted. ${ }^{18}$ To establish that $H$ pylori causes non-ulcer dyspepsia it has to be proved that the association is real and not due to chance occurrence of two common events. ${ }^{19,20}$ The increased prevalance of $H$ pylori in non-ulcer dyspepsia is due to the use of flawed control groups giving rise to misconceptions regarding the importance of $H$ pylori in non-ulcer dyspepsia. This misconception usually occurs due to a type 1 error, ${ }^{18}$ where a chance association is inevitable when multiple symptoms are analysed and no correction for the multiple comparisons is undertaken. Eight studies have reported no association between specific symptoms or syndromes of non-ulcer 


\section{Helicobacter pylori}

Associations

- over $50 \%$ of the world's population is infected

- $H$ pylori infection always causes gastric inflammation

- over $95 \%$ of duodenal ulcer patients are $H$ pylori positive

- $85 \%$ of gastric ulcer patients are $H$ pylori positive

- over $80 \%$ of chronic active gastritis patients are $H$ pylori positive

- epidemiological data indicate that $H$ pylori plays a role in the development of gastric cancer in the setting of multifocal chronic atrophic gastritis

- gastric B-cell lymphomas are associated with previous $H$ pylori infection and may regress following $H$ pylori eradication

- there is little evidence to suggest that $H$ pylori is a major factor in non-ulcer dyspepsia. It may have a role in a subgroup of patients

Box 3

\section{Helicobacter pylori}

Management:

- the outcome of $H$ pylori infection is dependent upon a combination of host factors, environmental factors and the virulence of the organism

- $H$ pylori can be eradicated in around $90 \%$ of patients by a 7 day course of triple therapy (omeprazole, clarithromycin, and tinidazole)

- once infected $H$ pylori usually remains for life until treated or it loses its niche due to gastric atrophy

- once eradicated in developed countries the reinfection rate with $H$ pylori in adults is below $1 \%$ per year

Box 4

\section{Learning points}

- non-ulcer dyspepsia is a heterogenous disorder including 'ulcer-like', 'reflux-like', 'dysmotility-like' and 'non-specific' dyspepsia

- differential diagnosis includes irritable bowel syndrome and reflux eosophagitis

- H pylori may play a role in a small sub-group of patients

- $H$ pylori eradication in non-ulcer dyspepsia is controversial

- management of non-ulcer dyspepsia is difficult. Patients need reassurance and may respond to changes in life style

- empirical treatment with acid suppression, $H$ pylori eradication or prokinetic drugs may be tried if symptoms are persisent and troublesome

dyspepsia and $H$ pylori positivity in patients with functional dyspepsia. One proposal is that $H$ pylori causes symptoms when there is increased neutrophil activity in association with intraluminal acid. ${ }^{21}$ Pain, it is suggested, originates from paracrine neurotransmitters which have been stimulated by inflammation and patient variability explains the symptom variability in non-ulcer dyspepsia. ${ }^{8}$ However the intermittent occurrence of symptoms of non-ulcer dyspepsia cannot be explained by the presence of active gastritis which is unlikely to fluctuate. ${ }^{22}$ Nearly one-third of non-ulcer dyspepsia cases are related to irritable bowel syndrome ${ }^{23,24}$ and some patients have pathological gastro-oesophageal reflux. ${ }^{25}$

Increased concentration of immunoreactive-somatostatin and immunoreactive-Substance $\mathbf{P}$ in the gastric mucosa of 'ulcer like' non-ulcer dyspepsia when compared to 'motility like' non-ulcer dyspepsia and peptic ulcer syndrome suggests that there may be two distinct subgroups, with non-ulcer dyspepsia not being only a stage within the spectrum of peptic ulcer disease. ${ }^{26}$

\section{Management}

The management of non-ulcer dyspepsia is difficult. Patients need reassurance, especially about the absence of any serious disease. Life-style modification may be helpful such as avoiding alcohol and coffee, losing weight and counselling to relieve anxiety, stress, and depression. Drugs have not proven to be effective in controlled trials but may work in day-to-day practice, albeit through a placebo effect. Nearly $60 \%$ of the patients benefit from placebo treatment. ${ }^{27}$ Drugs should only be used if the risk: benefit ratio is extremely low. They should also be avoided if symptoms have persisted for many years without compromising the quality of life. When prescribed, medication should be given for as short a time as possible. ${ }^{6}$

$H$ pylori eradication in non-ulcer dyspepsia remains controversial. O'Morain has shown that $H$ pylori eradication kept his non-ulcer dyspepsia patients asymptomatic at one year while his $H$ pylori positive patients continued to be symptomatic. However, his study was open, not blinded. Numerous other trials have been done using bismuth or antibiotics, singly or together. The reason why a clear picture has not emerged from these trials is manifold. Bismuth darkens the stool and hence it is difficult to perform a double-blind trial. Apart from having an anti- $H$ pylori effect bismuth also binds to mucus glycoproteins which reduces acid attack on the gastric mucosa ${ }^{29}$ inhibits pepsin,${ }^{30}$ stimulates prostaglandin synthesis by the gastric mucosa, ${ }^{31}$ increases mucosal bicarbonate secretion ${ }^{32}$ and inhibits peptic degradation of epidermal growth factor.$^{33}$ Using antibiotics alone to eradicate $H$ pylori also confounds the issue as they have their own gastrointestinal side effects.

\section{Conclusions}

In summary there is little evidence that $H$ pylori is a major player in the pathogenesis of non-ulcer dyspepsia. There is some suggestion that it may have a role in a subgroup of patients, perhaps causing hyperacidity as a result of hypergastrinaemia and leading to an increase in the parietal cell mass. This may have some effect upon gastric motility. Large, well-controlled, clinical trials are needed to answer these questions, until then treatment will remain empirical.

1 Colin-Jones DG, Bloom B, Bodermar G et al. Management of dyspepsia: report of a working party. Lancet 1988; 1: 576-9.

2 palley NJ, Colin-Jones D, Koch KL, et al. Talley NJ, Colin-Jones D, Koch KL, et al. Functional dyspepsia: A classification with guidelines for diagnosis and management. Gastroenterol Int 1991; 4: 145

3 Talley NJ, Zinsmeister AR, Schleck CD, Melton III LJ. Dyspepsia and dyspepsia subgroups: a population-based study. Gastroenterology 1992; 102: 1259-68.

4 Talley NJ, Phillips SF, Bruce B, et al. Relation among personality and symptoms in nonulcer dyspepsia and the irritable bowel syndrome. Gastroenterology 1990; 99: 327-33.

5 Malagelada JR. Gastrointestinal motor disturbances in functional dyspepsia. Scand $\mathcal{F}$ Gastro enterol 1991; 26 (suppl 182): 29-32.

6 Holtman G Talley NJ. Functional dyspepsia. Coltman $G$, Talley $\mathrm{NJ}$. Functional dyspepsia. 1993; 45: 918-30.

7 Lambert JR. The role of Helicobacter pylori in nonulcer dyspepsia. A debate. Gastroenterol Clin $N A m$ 1993; 22: 141 - 51.

8 Tytgat GNJ, Noach LA, Rauws EAJ. Is gastroduodenitis a cause of chronic dyspepsia? Scand $\mathcal{F}$ Gastroenterol 1991; 26: (suppl 182) 33-9.
9 Graham DY, Opekum A, Lew GH, et al. Ablation of exaggerated meal-stimulated gastrin Ablation of exaggerated meal-stimulated gastrin release in duodenal ulcer patients after clearance of Helicobacter (Campylobacter) pylori

10 McColl KE, Fullarton GM, Nujumi AM, et al. Lowered gastrin and gastric acidity after eradication of Campylobacter pylori in duodenal ulcer (letter). Lancet 1989; 2: 499.

11 Toukan AU, Kamal MF, Amr SS, et al. Gastroduodenal inflammation in patients with nonulcer dyspepsia: controlled endoscopic and morphometric study. Dig Dis Sci 1985; 30: 313.

12 Czinn SJ, Bertram TA, Murray PD, et al. Relationship between gastric inflammatory al. sponse and symptoms in patients infected response and symptoms in patients infected with 26 (suppl 181): 33 .

13 Moore SC, Malagelada JR, Shorter RG, et al. Interrelationships among gastric mucosal morphology, secretion and molity in peptic ulcer phology, secretion and molity in

14 Lambert JR, Dunn K, Borromeo M, et al. Campylobacter pylori - a role in non-ulcer dyspepsia? Scand $\mathcal{F}$ Gastroenterol 1989; 160 (suppl): 7-13. 
15 Marshall BJ. Campylobacter pylori: addressing the controversies. In: Menge $\mathrm{H}$, Gregor $\mathrm{M}$ Tytgat GNJ, eds. Campylobacter pylori. Berlin: Springer-Verlag, 1988; p235.

16 Wyatt JI, Rathbone BJ, Heatley RV, et al. Campylobacter pylori and history of dyspepsia in Campylobacter pylori and history of

17 McCarthy C, Patchett S, Collins R, et al. Long term effect of Helicobacter pylori eradication in nonulcer dyspepsia. Gastroenterology 1991; 100: A121.

18 Talley NJ. The role of Helicobacter pylori in nonulcer dyspepsia. A debate-against. Gastroenterol Clin N Am 1993; 22: 153-67.

19 Hill AB. The environment and disease: association or causation? Proc $R$ Soc Med 1965; 58: 295-300.

20 Rotham KJ. Causes. Am $\mathcal{F}$ Epidemiol 1976; 104: 587-92.

21 Deluca VA. No acid, no polyps. No 'active' gastritis, no dyspepsia: A proposal. $\mathcal{f}$ Clin gastritis, no dyspepsia: A propd
Gastroenterol 1989; 11: 127-31.

22 Talley NJ. Non-ulcer dyspepsia: epidemiology, natural history and association with Helicobacter pylori. In: Marshall BJ, McCallum R, Guerrant pylori. In: Marshall BJ, McCallum R, Guerrant
$\mathrm{R}$, eds. Helicobacter pylori, peptic ulceration and $\mathrm{R}$, eds. Helicobacter pylori, peptic ulceration and
gastritis. Cambridge: Blackwell, 1991; gastritis.
pp 34-45.
23 Talley NJ. Spectrum of chronic dyspepsia in the presence of the irritable bowel syndrome. Scand $\mathcal{F}$ Gastroenterol 1991; 26 (suppl 182): 7-10.

24 Talley NJ, Piper DW. The association between non-ulcer dyspepsia and other gastrointestinal disorders. Scand $¥$ Gastroenterol 1985; 20: disorders.

25 Fink SM, Barwick KW, Deluca V, et al. The association of histologic gastritis with gastroassociation of histologic gastritis with gastrooesophageal reflux and delayed gastric empty

26 ing. F Clin Gastroenterol 1984; 6: $301-9$. 26 Kaneko $\mathrm{H}$, Mitsuma $\mathrm{T}$, Uchida $\mathrm{K}$, et al. and calcitonin gene-related peptide concentrations of the human gastric mucosa in patients with nonulcer dyspepsia and peptic ulce disease. Am f Gastroenterology 1993; 88: 898-904.

27 Talley NJ, Phillips SF. Non-ulcer dyspepsia: potential causes and pathophysiology. Ann Intern Med 1988; 108: 865-79.

28 O'Morain C. Helicobacter pylori and non-ulcer dyspepsia. Gastroenterology 1992; 103: 341.

29 Tasman-Jones C, Maher C, Thomsen L, et al. Mucosal defences and gastro-duodenal disease. Digestion 1987; 37 (suppl 2): 1-7.
30 Rokkas T, Sladen GE, Bismuth: effects on gastritis and peptic ulcer. Scand $\mathcal{F}$ Gastroenterol 1988; 142 (suppl): 82-6.

31 Konturek SJ, Brzozowski T, Drozdowicz D, et al. Gastroprotective and ulcer healing properties of bismuth salts. In: Menge $H$, Gregor $M$, Tytgat GNJ, Marshall BJ, eds. Campylobacter pylori. Berlin: Springer-Verlag, 1988;
pytgat pylori.

32 Shorrock CJ, Crampton JR, Gibbons LC, et al. Effect of bismuth subcitrate on amphibian gastroduodenal bicarbonate secretion. Gut 1989; 30: 917-21.

33 Slomiany BL, Bilski J, Sarosiek J, et al. Coloidal bismuth subcitrate (De-nol) inhibits peptic degradation of epidermal growth factor. Gastroenterology 1988; 94: A431.

\section{Decision making}

\section{Forthcoming articles in this series}

Is this patient fit for a thoractomy?

The treatment of osteoporosis

The management of renal artery stenosis

Treatment options for inoperable non-small cell carcinoma of the lung 